\title{
ANALISIS SIMULASI TEGANGAN RODA GIGI PADA FISHING DECK MACHINERY TIPE HIDROLIK
}

\author{
Stress Analysis Simulation of Gear Wheel for Fishing Deck Machinery Hydraulic \\ Type \\ Y. Martin* dan A. Suwandi \\ Program Studi Teknik Mesin, Universitas Pancasila, Srengseng Sawah Jagakarsa Jakarta 12640, Indonesia
}

Informasi artikel

Diterima: 25/03/2020 Direvisi : 08/05/2020 Disetujui: 28/06/2020

\begin{abstract}
Abstrak
Indonesia dikenal sebagai Negara dengan sumber daya alam yang melimpah, termasuk dibagian industri perikanan dan kelautan, yang dimana di setiap tahunnya tingkat konsumsi ikan meningkat disetiap tahunnya. Dengan meningkatnya kebutuhan ikan disetiap tahunnya, dibutuhkan alat tangkap ikan yang lebih efisien demi memenuhi permintaan produktivitas tersebut, salah satunya yaitu alat bantu tangkap ikan, yaitu fishing deck machinery tipe hidrolik. Alat ini menggunakan roda gigi untuk dapat memutar tiang pengangkatnya. Berdasarkan fungsi tersebut, komponen roda gigi menjadi bagian yang penting dalam menopang beban tiang dan kompoenen lainnya yang bergerak memutar. Roda gigi yang dipakai adalah jenis roda gigi lurus. Untuk mendapatkan hasil analisis tegangan roda gigi menggunakan bantuan software Solidwork, sedangkan untuk desainnya digunakan software Inventor. Dengan mendapatkan hasil analisis tegangan roda gigi ini, dapat mengoptimalkan pemilihan dimensi serta material yang digunakan untuk aplikasinya.
\end{abstract}

Kata Kunci: tegangan, roda gigi lurus, material, simulasi.

\begin{abstract}
Indonesia is known for its abundant natural resources, including in the fisheries and marine industry, which in each year the level of fish consumption increases every year. With the increasing need for fish every year, more efficient fishing gear is needed to conform to the demand for productivity, one of which is a fishing gear, which is a hydraulic type of fishing deck machinery. This tool uses gears to be able to rotate the lifting pole. Based on this function, the gear component becomes an important component in supporting the load of the pole and other rotating components. The gear used is a straight gear type. To get the results of the analysis of gear tension using the help of Solidwork software, while for the design used Inventor software. By getting the results of this gear tension analysis, it can optimize the selection of dimensions as well as the material used for its application.
\end{abstract}

Keywords: stress, straight gears, material, simulation.

\footnotetext{
* Penulis Korespondensi. Handphone: 081367988779

email : yosuamartin7@gmail.com
} 


\section{PENDAHULUAN}

Indonesia memiliki garis pantai terpanjang kedua didunia yaitu dengan panjang $104.000 \mathrm{~km}^{2}$, dengan total luas laut Indonesia yaitu 3,110 juta $\mathrm{km}^{2}$ dan pulau sebanyak 17.504 pulau yang tersebar dari sabang sampai merauke (Komunikasi, 2018). Dalam sektor perikanan Indonesia diperkirakan mencapai US\$ 82 miliar per tahun (Pursetyo et al., 2015). Dalam melakukan penangkapan ikan, penggunaan alat penangkapan ikan perlu diatur agar tidak berdampak negatif pada habitat ikan dan sumber daya ikan, serta manfaat lain dari jasa lingkungan yang tersedia di perairan.

Dalam penggunaan alat penangkapan ikan saat ini sebagai fasilitas utama dalam pemanfaatan ikan, sangat perlu diatur agar sedemikian rupa tidak berdampak negatif baik pada sumber daya ikan serta lingkungan perairan yang ada di Indonesia, serta manfaat lain dari jenis jasa lingkungan yang ada di perairan (Tanjung dan Suwandi, 2017).

Salah satu alat yang digunakan untuk melakukan penangkapan ikan yaitu dengan menggunakan mesin tangkap ikan dengan menggunakan sistem hidrolik atau disebut juga sebagai Fishing Deck Machinery (Cahyadi dan Suwandi, 2017). Salah satu jenis Fishing Deck Machinery yang banyak digunakan pada kapal penangkap ikan ukuran 5-10 GT adalah tipe hidrolik .

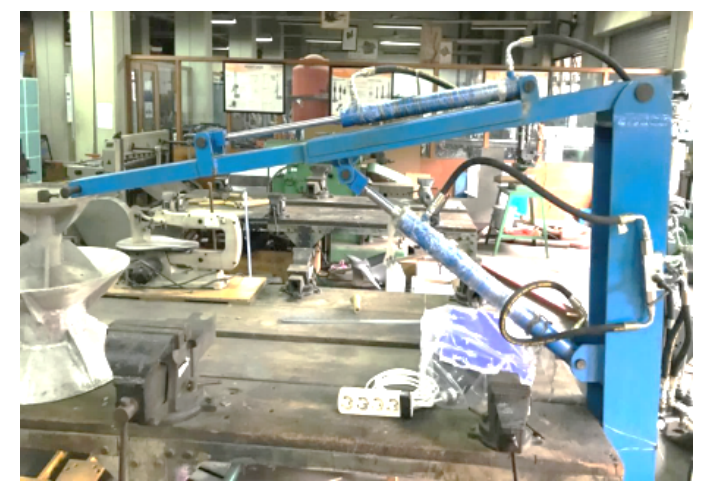

Gambar 1 Fishing Deck Machinery Tipe Hidrolik Sisi Samping

Gambar 1 memperlihatkan Fishing Deck Machinery tipe hidrolik, namun pada alat ini masih belum adanya sistem roda gigi, yang dimana roda gigi tersebut berfungsi untuk mengkonversi torsi dan kecepatan putaran dari mesin menjadi torsi dan kecepatan yang berbeda-beda untuk diteruskan ke penggerak roda gigi dalam menggerakan tiang utama.
Roda gigi adalah salah satu komponen penting dalam dunia mekanika, digunakan untuk meningkatkan atau menurunkan torsi, merubah arah gerak serta mentransmisikan daya dari suatu sistem gerak (Mott, 2009).

Roda gigi merupakan suatu elemen mesin yang berfungsi untuk mentransmisikan daya dan putaran poros sehingga system mekanisme pada mesin dapat bekerja sesuai dengan fungsinya. Ada beberapa yang harus diperhatikan dalam perancangan roda gigi, yaitu seperti dimensi, gaya, dan torsi dan tegangan-tegangan yang bekerja pada roda gigi, karena apabila hal ini tidak dilakukan maka akan menyebabkan roda gigi tidak dapat digunakan dengan baik.

Perancangan roda gigi yang tidak dapat beroperasi dengan baik seperti kontak antar gigi yang kasar mengakibatkan gerak antar hihi tidak sempurna sehingga mengakibatkan ketidakseragaman gaya kontak antar satu gigi dengan gigi lainnya. Kerusakan roda gigi dapat disebabkan oleh berbagai faktor termasuk pelumasan yang tidak memadai, kondisi operasi, material dan proses manufaktur yang tidak sesuai dengan spesifikasi (Erinofiardi, et al. 2013). Roda gigi merupakan komponen yang paling banyak digunakan karena beberapa kelebihannya, yaitu:

- $\quad$ Tidak ada slip pada pemindahan gaya (pada rasio putaran yang tetap, tanpa tergantung pada besarnya beban) sehingga efisiensi tinggi

- Umur dari roda gigi dan reliabilitasnya tinggi

- Mampu untuk menahan beban lebih besar

- Perawatannya mudah dan susunannya kompak

Roda gigi sering digunakan karena dapat meneruskan putaran dan daya yang lebih bervariasi dan lebih kompak daripada menggunakan alat transmisi yang lainnya, selain itu roda gigi memiliki beberapa kelebihan dibandingkan dari alat transmisi lainnya, yaitu:

- Sistem transmisi yang lebih sederhana, putaran lebih tinggi dan daya yang besar.

- Sistem yang sama sehingga konstruksinya sederhana.

- Kemampuan menerima beban yang lebih tinggi.

- Efisiensi pemindahan dayanya lebih tinggi karena faktor terjadinya slip sangat kecil. 
- Kecepatan transmisi roda gigi dapat ditentukan sehingga dapat digunakan dengan pengukuran yang kecil dan daya yang besar.

Roda gigi harus mempunyai perbandingan kecepatan sudut tetap antara dua poros. Di samping itu terdapat pula roda gigi yang perbandingan kecepatan sudutnya dapat bervariasi. Ada pula roda gigi dengan putaran yang terputus-putus. Dalam teori, roda gigi pada umumnya dianggap sebagai benda kaku yang hampir tidak mengalami perubahan bentuk dalam jangka waktu lama (Hantoro dan Tiwan, 2012).

Menurut Riyanto, dalam jurnal yang berjudul design penarik jaring (power block) menjelaskan bahwa purse sein merupakan alat bantu penangkap ikan yang sering dijumpai namun penggunaan masih membutuhkan $A B K$ yang banyak sehingga tidak efisien (Riyanto et al., 2016).

Tujuan dari penelitian untuk mendapatkan hasil analisis simulasi dari tegangan tarik roda gigi yang bekerja pada fishing deck mechinerey tipe hidrolik. Hasil dari analisi tersebut, nantinya digunakan sebagai acuan pemilihan dimensi dan material yang tepat untuk memaksimalkan fungsi dari alat tersebut sehingga dapat bergerak secara optimal.

\section{METODOLOGI}

Gambar 2 memperlihatkan diagram alir dari tahapan penelitian yang dilakukan, diawali dengan Studi literatur dan studi lapangan merupakan tahapan awal dalam melakukan penelitian, sehingga perancangan mendapatkan hasil yang baik dan alat yang dihasilkan dari perancangan ini dapat berguna serta sesuai dengan kebutuhan yang dibutuhkan.

Selanjutnya adalah proses perhitungan, tahapan ini bertujuan untuk menghitung menentukan dimensi, tebal, serta material yang akan digunakan pada roda gigi, tahap ini merupakan tahapan awal dalam proses pembuatan roda gigi untuk melakukan Analisis Tegangan Roda Gigi Pada Fishing Deck Machinery Tipe Hidrolik.

Dengan banyaknya jenis atau model roda gigi yang ada, penelitian ini akan berfokuskan pada Roda Gigi Lurus. Roda Gigi Lurus umumnya digunakan untuk memindahkan putaran antar 2 (dua) poros yang sejajar dengan gigi-gigi berbentuk lurus dan sejajar dengan poros yang digunakan, dan biasanya digunakan pada kecepatan rendah sampai kecepatan sedang. Hal tersebut yang menjadi alasan utama dalam pemilihan jenis roda gigi lurus tersebut.

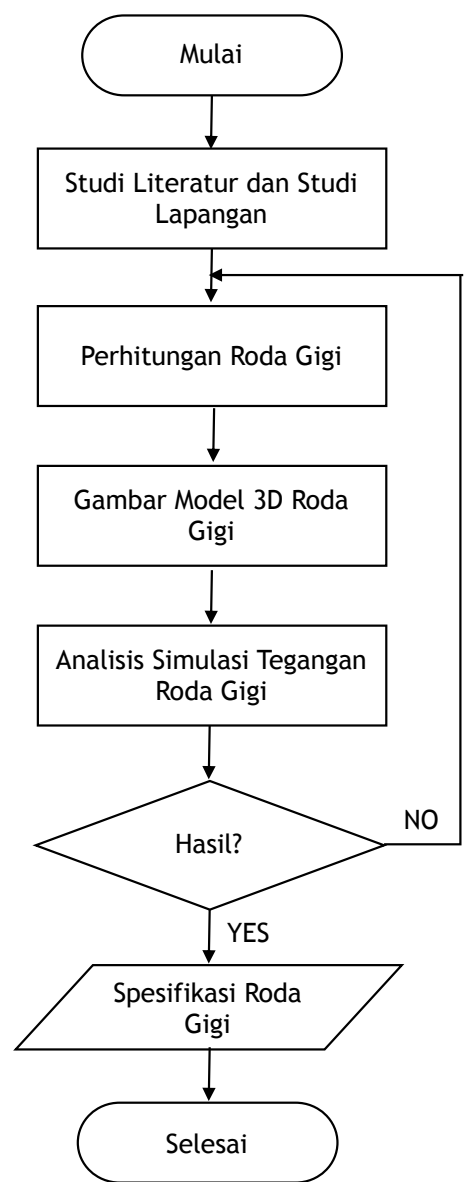

Gambar 2 Diagram Alir Tahapan Penelitian

Gambar 3 memperlihatkan bagianbagian dari gigi lurus yang digunakan

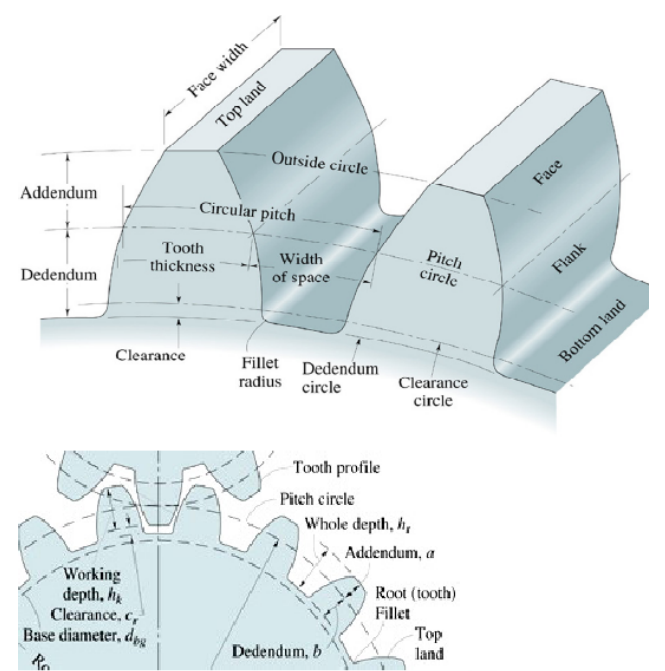

Gambar 3 Bagian Roda Gigi Lurus (Bhandari, 2010) 
Beberapa dimensi yang terdapat pada roda gigi dapat dijadikan acuan dalam perancangan roda gigi lurus. Dimensi-dimens roda gigi meliputi diameter roda gigi, tinggi kepala, tinggi kaki, kelonggaran kepala, diameter lingkaran kepala, diameter lingkaran kaki, kedalaman total, kedalaman penuh, tebal gigi dan jarak antar pusat roda gigi (Erinofiardi, et al. 2013).

Roda Gigi Lurus memiliki bagian-bagian utama, diantaranya adalah (Marsis dan Agung, 2014):

1. Lingkaran Dasar (Base Circle) adalah lingkaran semu dengan diameter yang merupakan dasar pembentukan involut.

2. Lingkaran Referensi (Reference Circle) adalah lingkaran semu dengan diameter $d$, dimana kelilingnya merupakan hasil kali dari Pitch dengan jumlah gigi.

3. Pitch adalah panjang busur pada lingkaran referensi diantara dua involut yang berurutan.

4. Modul adalah parameter yang menentukan jumlah gighi bagi suatu lingkaran referensi yang tertentu.

5. Tebal Gigi (Tooth Thickness) adalah panjang busur pada lingkaran referensi diantara dua buah sisi pada satu gigi.

6. Sudut Tekan (Pressure Angle) adalah sudut terkecil antara garis normal pada involut dengan garis singgung pada lingkaran referensi di titik potong antara involut dengan lingkaran referensi. Menurut standar ISO sudut tekan berharga $20^{\circ}$.

7. Jarak Gigi adalah panjang busur pada lingkaran referensi diantara dua sisi gigi yang berseberangan.

8. Adendum adalah jarak radial antara lingkaran puncak dengan lingkaran refernsi.

9. Dedendum adalah jarak radial antara lingkaran referensi dengan lingkaran kaki.

10. Tinggi Gigi adalah jarak radial antara lingkaran puncak dengan lingkaran kaki.

11. Lebar Gigi adalah jarak antara kedua tepi roda gigi yang diukur pada permukaani referensi

Ada beberapa persamaan yang digunakan dalam merencanakan sebuah roda gigi lurus (Marsis dan Agung, 2014):

Modul $(M): M=D / Z$

Jumlah Gigi $(Z): Z=D / M$

Diameter Pitch (D) : $\mathrm{D}=\mathrm{Z} . \mathrm{M}$
Diameter Luar $(\mathrm{Da}): \mathrm{Da}=\mathrm{D}+2 \mathrm{M}$

$$
: D a=(Z+2) M
$$

Diameter Kaki (Df) : $\quad D f=D+2,32 \cdot M$

$$
\text { : } D f=(Z+2,32) M
$$

Adendum $(\mathrm{Ha}): \mathrm{Ha}=1 . \mathrm{M}$

Defendum (Hf) : $\mathrm{Hf}=1,16 . \mathrm{M}$

Tinggi gigi $(H): H=2,16 . M$

Jarak Pitch $(\mathrm{T}): \mathrm{T}=\pi . \mathrm{M}$

Lebar Gigi (B) : $B=10 . M$

Berdasarkan gambar 2, setelah dilakukan perhitungan, maka langkah selanjutnya adalah design model 3D dengan bantuan software, yaitu Solidworks. Pada analisis tegangan roda gigi dilakukan dengan menggunakan software Inventor. Dari hasil analisis yang dihasilkan, jika nilai tegangan yang dihasilkan belum memenuhi nilai von misses stress < kekuatan material, maka rancangan roda gigi perlu dihitung kembali. Apabila hasil desain pada tahap sebelumnya telah memenuhi nilai von misses stress < kekuatan material, maka didapatkan spesifikasi yang sesuai untuk direkomendasikan.

Setelah melakukan semua perhitungan yang dibutuhkan, selanjutnya yaitu tahapan simulasi. Seperti yang diperlihatkan pada gambar 3, yaitu tahap simulasi yang dilakukan.

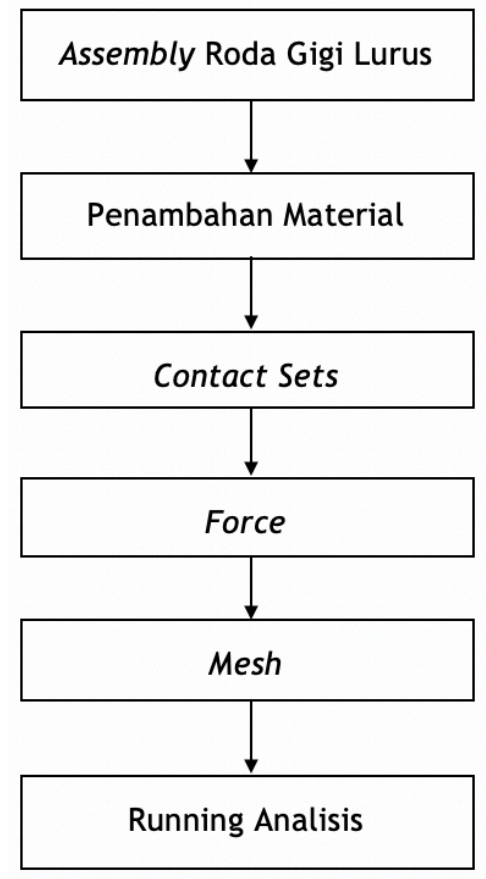

Gambar 3 Alur Tahapan Simulasi 
Pada gambar 3, dapat dijelaskan bahwa:

1. Assembly Roda Gigi Lurus

Tujuan dari assembly yaitu untuk mengetahui cocok atau tidaknya ukuran dari antar gear yang digabungkan seperti pada gambar 4 .

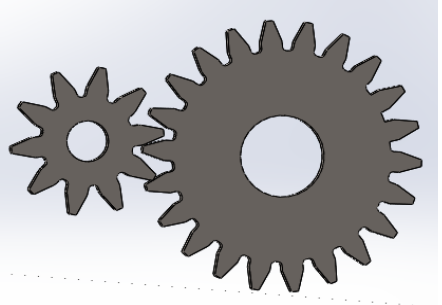

Gambar 4 Assembly

2. Penambahan Material

Material yang ditambahkan yaitu stainless steel seperti yang diperlihatkan pada gambar 5 .

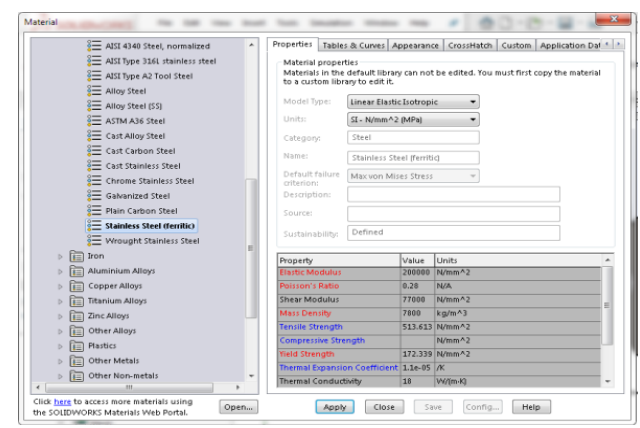

Gambar 5 Penambahan Material

\section{Contact Sets}

Contact sets yaitu titik temu (lihat gambar 6) antara gear kecil (sebagai penggerak) dengan gear besar (yang digerakkan) pada saat bergesekan.

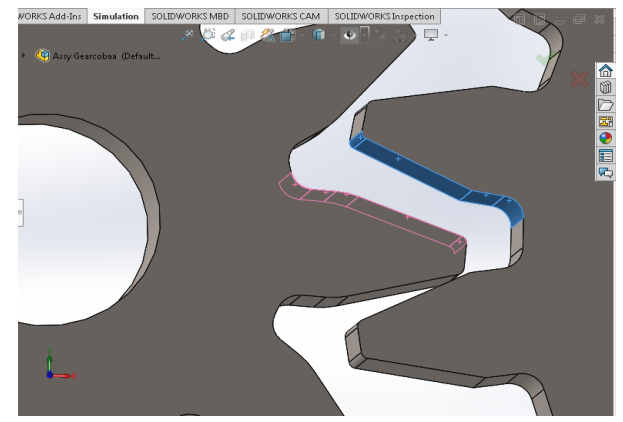

Gambar 6 Contact Sets
4. Force

Tekanan gaya dengan menggunakan parameter torsi motor yang tersedia dipasaran, yaitu: torsi 3,9 $\mathrm{Nm}$ proses input seperti pada Gambar 7.

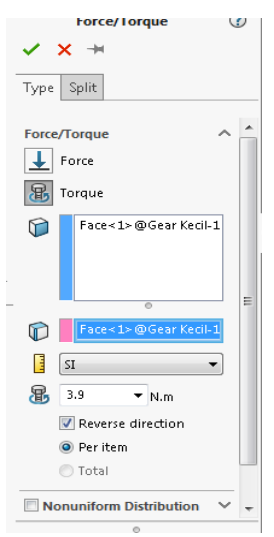

Gambar 7 Input Torsi

5. Mesh

Bertujuan untuk menganalisis statik pada gear yang akan digunakan seperti pada gambar 8 .

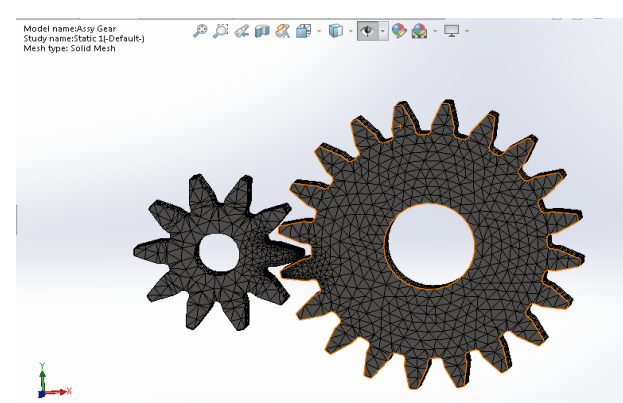

Gambar 8 Mesh

6. Running Analisis

Dimana tahap penghitungan dan analisi oleh software terhadap gaya dan konstrain serta parameter-parameter lainnya yang telah diberikan.

\section{HASIL DAN PEMBAHASAN}

Salah satu gungsi dari roda gigi lurus yaitu berfungsi untuk memindah putaran dari poros yang sejajar dan memindahkan gaya/beban yang berat dan biasanya digunakan pada kecepatan rendah sampai kecepatan sedang. Dengan menggunakan roda gigi eksternal (roda gigi lurus), akan mempermudah kinerja pada fishing deck machinery tipe hidrolik dikarenakan 2 (dua) kelebihan yang dimiliki, yaitu: 
1. Memiliki kemampuan menerima beban lebih tinggi sesuai dengan fishing deck machinery tipe hidrolik.

2. Kecepatan yang dimiliki roda gigi lurus termasuk dalam kecepatan rendah, yang dimana dalam penelitian ini kecepatan rendah yang dibutuhkan untuk menyesuaikan dengan fishing deck machinery tipe hidrolik.

Stainless steel adalah suatu baja paduan yang mengandung sedikitnya memiliki $11,5 \%$ krom berdasarkan komposisi pada berat yang dimiliki. Stainless steel juga memiliki sifat yang dimana tidak mudah korosi seperti pada logam baja umum yang lain. Stainless.steel berbeda dari baja lainnya yang terlihat pada kandungan kromnya. Dari sifat yang tahan terhadap air dan udara yang dimiliki oleh stainless steel, maka stainless steel tidak memerlukan suatu lapisan logam yang khusus dikarenakan lapisan pasif tipis yang dimiliki stainless steel akan cepat terbentuk kembali ketika mengalami suatu goresan. Stainless steel tipe 304 merupakan baja tahan karat yang serbaguna.dan paling banyak digunakan. Komposisi kimia, kekuatan mekanik, kemampuan las dan ketahanan korosinya sangat baik dengan harga yang relative terjangkau.

Dengan kandungan dan sifat yang dimiliki bahan stainless steel maka bahan atau material stainless steel sangat cocok untuk fishing deck machinery tipe hidrolik.

Sebelum melakukan perhitungan roda gigi, dalam melakukan penelitian ini Fishing Deck Machinary tipe hidrolik yang digunakan memiliki berat total $1.400 \mathrm{~kg}$ atau sama dengan 1,4 ton, dengan asumsi rincian berat sebagai berikut:

1. Berat Fishing Deck Machinery $=750 \mathrm{~kg}$

2. Berat maksimal dalam menangkap ikan = $650 \mathrm{~kg}$

3. Lebar batang utama $(H$-Beam $)=160 \mathrm{~mm}$ Dengan menggunakan persamaan yang ada pada bagian metodologi, maka dihasilkan spesifikasi roda gigi lurus yang digunakan seperti pada tabel 1. Gambar 9 memperlihatkan bagian gigi lurus dengan simbol, untuk detail dapat dilihat pada gambar 3.

Adapun diameter rencana roda gigi lurus telah ditentukan sebelumnya, yaitu: diameter $200 \mathrm{~mm}$ dan gear diameter $100 \mathrm{~mm}$, agar dimensi proporsional dengan batang yang akan digerakkan. Dengan menggunakan perbandingan diemeter roda gigi 1:2 yang bertujuan agar torsi yang dihasilkan lebih besar sehingga diameter yang dipilih (diameter $200 \mathrm{~mm}$ ) atau lebih besar dari diameter batang utama ( $\mathrm{H}$-Beam).

Tabel 1 Hasil perhitungan spesifikasi roda gigi lurus

\begin{tabular}{|c|c|c|c|c|}
\hline No & Besaran & Simbol & Satuan & Nilai \\
\hline 1 & Daya & $P$ & $\mathrm{hp}$ & 2,3 \\
\hline 2 & Kecepatan & $\mathrm{Np}$ & $\begin{array}{c}\text { putaran/ } \\
\text { menit }\end{array}$ & 1500 \\
\hline 3 & $\begin{array}{l}\text { Jumlah } \\
\text { Mata Gigi }\end{array}$ & Z & & 22 \\
\hline 4 & $\begin{array}{l}\text { Jumlah } \\
\text { Mata Gigi } \\
\text { Penggerak }\end{array}$ & Z & & 10 \\
\hline 5 & $\begin{array}{l}\text { Diameter } \\
\text { Roda Gigi }\end{array}$ & $D_{k}$ & $\mathrm{~mm}$ & 200 \\
\hline 6 & $\begin{array}{l}\text { Diameter } \\
\text { Roda Gigi } \\
\text { Penggerak }\end{array}$ & $\mathrm{D}_{\mathrm{p}}$ & $\mathrm{mm}$ & 100 \\
\hline 7 & $\begin{array}{l}\text { Modul } \\
\text { Penggerak }\end{array}$ & M & $\mathrm{mm}$ & 10 \\
\hline 8 & Pitch & $\mathrm{P}$ & $\mathrm{mm}$ & 3,14 \\
\hline
\end{tabular}

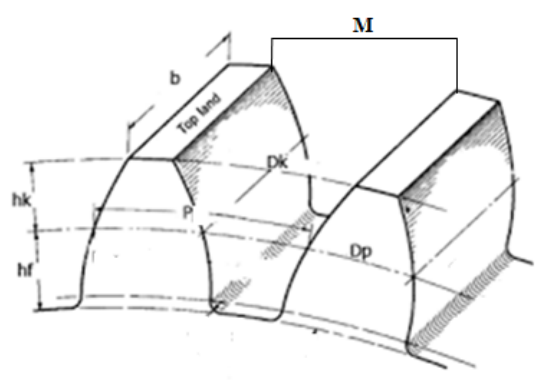

Gambar 9 Simbol pada Bagian Roda Gigi (Bhandari, 2010)

Selain perhitungan roda gigi, perhitungan lainnya yang dilakukan yaitu perhitungan spesifikasi motor listrik, yaitu sebagai berikut:

1. Arus

$$
\begin{aligned}
I & =\frac{\mathrm{P}}{(\mathrm{V} \times \operatorname{Cos} \varphi)} \\
& =\frac{\mathbf{1 5 0 0}}{(220 \times 0,78)} \\
& =\frac{1500}{171,6}=8 \text { Ampere }
\end{aligned}
$$

2. Daya

$$
\begin{aligned}
\mathrm{P} & =\mathrm{V} \times \mathrm{I} \times \operatorname{Cos} \varphi \\
& =220 \times 8 \times 0,78 \\
& =1372,8 \mathrm{Watt} \\
& =\frac{1372,8}{745,7}=2,3 \mathrm{hp}
\end{aligned}
$$

3. Torsi

$$
\begin{aligned}
& =\frac{\mathrm{p}}{\mathrm{w}} \\
& =\frac{1372,8 \text { watt }}{350}=3,922 \mathrm{Nm}
\end{aligned}
$$


Berdasarkan perhitungan yang telah dilakukan, maka didapatkan parameter dengan nilai torsi 3,9 Nm. Setelah melakukan semua perhitungan yang dibutuhkan, selanjutnya yaitu tahapan simulasi. Seperti yang diperlihatkan pada gambar 3, dimana akan dihasilkan analisis yang telah dilakukan dengan torsi 3,9 Nm menghasilkan nilai von Mises stress maksimal adalah 8,94 $\mathrm{MPa}$ seperti yang terlihat pada gambar 12 .

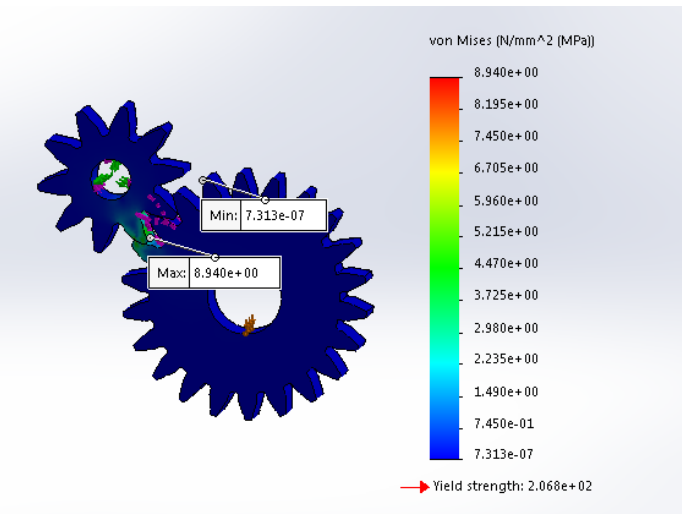

Gambar 12 Tegangan yang terjadi dengan Torsi Motor 3,9 Nm

Dapat dilihat bahwa desain telah memenuhi kriteria nilai von misses stress < kekuatan material (SS630), yaitu: 8,94 MPa $<900 \mathrm{MPa}$.

\section{SIMPULAN}

Berdasarkan hasil perhitungan dan analisis yang telah dilakukan, maka dihasilkan kesimpulan bahawa Spesifikasi roda gigi: Jenis Roda Gigi yang digunakan Roda Gigi Lurus, dengan nilai Torsi yaitu $3,9 \mathrm{Nm}$, nilai Daya $(\mathrm{P})$ yaitu $2,3 \mathrm{hp}$, Kecepatan (Np) yaitu 1500 putaran/menit, Jumlah Mata Gigi Penggerak (Z) yaitu $10 \mathrm{~mm}$, Jumlah Mata Gigi (Z) yaitu 20mm, Diameter Roda Gigi (D) yaitu $200 \mathrm{~mm}$, Diameter Roda Gigi Penggerak (D) yaitu $100 \mathrm{~mm}$, Modul (M) yaitu $10 \mathrm{~mm}$, Pitch (P) yaitu 31,4mm, serta Koefisien Elastis yaitu sebesar $191 \mathrm{n} / \mathrm{mm}$ dan dengan penggunaan motor listrik yang memiliki torsi $3,9 \mathrm{Nm}$.

\section{UCAPAN TERIMA KASIH}

Penelitian ini didukung oleh Hibah Penelitian Terapan Unggulan Perguruan Tinggi Tahun 2019 dari Kemenristekdikti dan LPPM Univeristas Pancasila dengan kontrak penugasan penelitian nomor 2318/LPPM/UP/V/2019.

\section{DAFTAR PUSTAKA}

Bhandari, V. B. 2010. Design of Machine Elements. Tata McGraw-Hill Education. New Delhi.

Cahyadi, R. dan A. Suwandi. 2017 Perancangan Alat Bantu Penangkap Ikan (Fishing Deck Machinery) Untuk Peningkatan Produktifitas Nelayan. Seminar Nasional Sains dan Teknologi 2017, Fakultas Teknik Universitas Muhammadiyah Jakarta , 1-2 November 2017.

Erinofiardi, Kevin Asyarial dan Hendra. 2013. Perancangan Roda Gigi Lurus, Roda Gigi Miring Dan Roda Gigi Kerucut Lurus Berbasis Progaram Kumputasi. Jurnal Mechanical, Volume 4, Nomor 1, Maret 2013 hal. 16-21.

Hantoro S. dan T. Tiwan. 2012. Desain Profil Gigi Roda Gigi Lurus Dengan Sistem Koordinat. Teknoin, vol. 11 , no. 1 , hal. 13-24.

Komunikasi, Biro. 2018. Menko Maritim Luncurkan Data Rujukan Wilayah Kelautan Indonesia. Available At: https://maritim.go.id/menko-maritimluncurkan-data-rujukan-wilayah-

kelautan-indonesia/. Kementerian Koordinator Bidang Kemaritiman dan Investasi RI (Accessed: 24 September 2019).

Marsis, W. P. and Agung, D., 2014. Analisa Perancangan Roda Gigi Lurus Menggunakan Mesin Konvensional. SINTEK JURNAL: Jurnal Ilmiah Teknik Mesin, 8(1).

Mott, Robert L. 2009. Elemen-Elemen Mesin Dalam Perancangan Mekanis: Perancangan Elemen Mesin Terpadu Buku 1. Penerbit ANDI. Sleman, Yogyakarta.

Pursetyo, Kustiawan Tri., Wahju Thajaningsih, Heru Pramono. 2015 Perbandingan Morfologi Kerang Darah Di Perairan Kenjeran Dan Perairan Sedati. J. Ilm. Perikan. dan Kelaut. dan Kelaut., vol. 7, no. 1, hal. 31-33.

Riyanto, Agus., Sugeng dan Sansan. 2016. Desain Mesin Penaring Jaring (Power Block) Bertenaga Hidrolik Untuk Mini Purse Seine. Buletin Teknik Litkayasa (BTL) Vol. 14 No. 2 Desember 2016 : 6772.

Suwandi, A., Zariatin, D.L., Sulaksono, B., Prayogi, E. and Anggada, A., 2018. Perancangan Konsep Alat Bantu Penangkapan Ikan (Fishing Deck Machinery) Tipe Hidrolik untuk Kapal> 5 
GT. SEMRESTEK PROSIDING, Universitas Pancasila. November 2018. pp.313-319.

Tanjung, Agung Satria dan A. Suwandi. 2017 Manufaktur Alat Bantu Penangkapan Ikan (Fishing Deck Machinery) Produksi Dalam Negeri. Seminar Nasional Sains dan Teknologi 2017, Fakultas Teknik Universitas Muhammadiyah Jakarta , 1-2 November 2017. 